\title{
Inter-Enterprise Architecture and Internet of the Future
}

\author{
Alix Vargas ${ }^{1}$, Andrés Boza ${ }^{1}$, Llanos Cuenca ${ }^{1}$, and Ioan Sacala ${ }^{2}$ \\ ${ }^{1}$ Centro de Investigación en Gestión e Ingeniería de Producción (CIGIP), \\ Universitat Politècnica de València, Camino de Vera s/n Ed $8 \mathrm{G}-1^{\circ}$ y $4^{\circ}$ planta Acc D \\ (Ciudad Politécnica de la Innovación) Valencia Spain \\ alvarlo@posgrado.upv.es, \{aboza,1lcuenca\}@cigip.upv.es \\ ${ }^{2}$ University Politehnica Bucharest, Faculty of Automatics and Computer Science, \\ 313, Splaiul Independetei, 60042 Bucharest Romania \\ sacalaioan@yahoo.com
}

\begin{abstract}
This paper proposes the concept of Inter-Enterprise Architecture (IEA), which seeks the application of tools and methodologies developed in the Enterprise Architecture (EA) field for the individual firm, adapting to an environment of collaboration between several companies that make networks or supply chains, in order to facilitate the integration and interoperability of their collaborative processes in line with its IS/IT (Information Systems/ Information Technology) to harmonize the joint processes, reduce risk and duplication, increase service and customer responsiveness, reduce technology costs and align the joint business to IS/IT.
\end{abstract}

Keywords: strategic alignment, enterprise collaboration, enterprise architecture.

\section{Introduction}

The current business environment is dominated by globalization, and the biggest consequence of this effect is the increase of competition, not only between companies but also between supply chains and networks. As a result, supply chains and networks are now looking to enforce collaborative agreements, which would produce more efficient workflow, flexibility, effectiveness, agility and coordination between chain links. In order to achieve proper synchronization and organization, every chain link must be provided with sufficient information and communication technology to further facilitate their operational integration. In achieving this level of cooperation, there has been an increase in the number of publications that combines topics of strategic alignment and enterprise collaboration. To fuse these principles, current research proposes the use of enterprise engineering through utilizing enterprise architecture.

In order to explain the origin of that formulation, state of the art research has been conducted in three areas: strategic alignment, enterprise architecture, and enterprise collaboration; this has helped to identify trends in current literature, studying the models that have been presented and their relationships with one another, structuring main concepts and associated issues, analysing main ideas and common points, and 
identifying a large gap in the literature, due to the fact that there is currently not any documentation tying these three fields of research together. As a result of this gap, the concept of Inter-Enterprise Architecture (IEA) is proposed, using the tools and methodologies of enterprise architecture, which have been developed for the individual enterprise, but adapting them in a collaborative environment between several enterprises making up supply chains and networks. This will facilitate the collaboration and integration process between enterprises and their information and technology systems, supporting joint processes, reducing risks and redundancies, increasing customer service and responsiveness, reducing technology costs and allowing for alignment on multiple levels: joint business processes, and IS/IT. This level of integration has made the Internet vitally important to all business environments. Therefore, the link between the topics of IEA and Internet of the future is evident.

\section{Future Internet and Internet of Things}

Currently, it is well known that the Internet is used by everyone in many different ways. Over time, the Internet has become a necessity in business environments, but many SMEs cannot use it as a management and operational tool. In order for the Internet to become useful as a real universal business system used by collaborative networks, it is necessary than society research and industry work jointly and coordinately.

According to the European Commission, Internet of Things (IoT) is an integrated part of the future Internet and could be defined as a dynamic global network infrastructure with self configuring capabilities based on standard and interoperable communication protocols where physical and virtual "things" have identities, physical attributes, virtual personalities and use intelligent interfaces, and are seamlessly integrated into the information network[1].

The current research proposes that the concept of an IEA describes how an instrument assures strategic alignment between business and IT in collaborative networks. Thus, it is necessary to also understand the interactions between virtual and physical worlds. Enterprise Architecture and Modelling based on the Internet of Things makes sense because of the proliferation of cheap sensors heralded by the Internet of Things. With this kind of technology being utilized, collaborative enterprise efforts will achieve a better understanding of the joint process of allowing business decisions to be made in real time, even without direct human intervention.

\section{Conceptualization}

So far, in the context of the current research, three papers have been published that consolidate the state of the art research in three main topics: strategic alignment, enterprise collaboration and enterprise architecture $[2,3,4]$. In this section, we are going to brief the reader in a general way about the principal conclusions deduced in 
these papers, after a deep analysis of the literature. We invite the reader of this paper to check these papers in order to enhance their knowledge of these topics.

\subsection{Conceptualization of Strategic Alignment}

According to the most important elements provided for several authors, in [4], we suggested the following definition for strategic alignment: "The strategic alignment of business and IS/IT is a dynamic and continuous process that enables integration, adjustment, consistency, understanding, synchronization and support between business strategies and strategies of IS / IT, in order to contribute and maintain the correct performance of the organization, creating a competitive advantage that is sustained over time".

The principal models in strategic alignment have been proposed for [5] and [6], Strategic Alignment Model (SAM) and Alignment Maturity Model (AMM), respectively. The field of strategic alignment is reinforced by SAM but their bases are theoretical and not practical. AMM, presents a practical component that SAM does not have, this model is based on the concepts that are treated conceptually in the SAM, but incorporating a practical aspect to the field of strategic alignment, proposing a model to measure the degree of maturity of the business and IS/ IT alignment, enabling the company that applied to identify, how it is, where and how to improve [2].

The principal elements identified in this field are: business strategy, organizational and processes infrastructure, IS infrastructure, IS / IT strategy, IT conceptualisation, maturity model alignment, applications and services portfolio, alignment heuristics, strategic dependencies model and portfolio applications $[5,6,7]$.

\subsection{Conceptualization of Collaboration}

In [3], business collaboration is defined as: "A joint process between members of the $S C$, where the decisions are made jointly, based on the information shared and exchanged on a bilateral form, achieving coordinate and synchronize joint activities to meet customer requirements and achieve process efficiency sets to generate a mutually beneficial”.

According to [8], the collaboration process consists of six activities. However, this generic process has not taken a certain crucial aspect into account: the definition of how to share benefits equitably to ensure the stability of the collaboration [9]. The solution to this problem is provided by [10], which proposed the definition of a system of compensatory payments, which may agree with the definition phase of the negotiation and exception handling and can be implemented when evaluating the results. Another previously unconsidered aspect in this generic process is the need for feedback between the parties once it has completed the process of collaboration in the stipulated horizon, which also must review the plan and modify if necessary. Thus, we proposed in [4], the following enterprise collaboration process: 1) Definition and collaboration agreement, 2) Planning in the local domain, 3) Plan of exchange, 4) Negotiation, exception handling and compensation system, 5) Execution, 6) Measurement of results and implementation of compensation plan, and 7) Feedback and review of the plan. 


\subsection{Conceptualization of Enterprise Architecture}

In [3], Enterprise Architecture is defined as: "A discipline that provides a set of principles, methods, models and tools used for analysis, design and redesign of a company, thus allowing to represent and document the elements that form the company (such as organizational structure, business processes, systems information and technology infrastructure) and the relations, organization and joints between these elements, allowing the company to be represented in a holistic and integrated perspective, in order to achieve the business objectives and facilitate decision-making processes"

In recent years, several researchers have proposed enterprise architectures, among which stand out: CIMOSA [11], GIM-GRAI [12], PERA and GERAM [13], IE-GIP [14, 7], TOGAF-ADM [15], ARDIN [16] and ARIS [17].

The common elements that handle these enterprise architectures are: methodology, framework and language modeling [3].The definition of a methodology facilitates the implementation of the architecture [18]; the framework allows a graphic and simple structure of the elements that make up the enterprise [19] and how these elements are related [18]; furthermore, modeling language allows for modeling, organization and understanding of the relationships between elements of the enterprise[3].

\section{$4 \quad$ Research Contribution}

It has been crucial to prepare state of the art research in three areas: strategic alignment, enterprise architecture, and enterprise collaboration; this has helped identify trends in current literature, studying the models that have been presented and their relationships with one another, structuring main concepts and associated issues, analysing main ideas and common points, and identifying a large gap in the literature, due to the fact that there is not currently any documentation tying these three fields of research together.

As a result of this gap, the concept of Inter-Enterprise Architecture (IEA) is proposed, looking for applications of the tools and methodologies of enterprise architecture, which have been developed for the individual enterprise, but adapting them in a collaborative environment between several enterprises that make up supply chains and networks. This will facilitate integrative collaboration processes among enterprises with their information systems and technology systems, supporting joint processes, reducing risks and redundancies, increasing customer service and responsiveness, reducing technology costs and allowing for alignment on multiple levels: joint business processes, Information and Communication Technology (ICT). In Fig. 1, currently complete work is summarized, and in the spotlight, the field of intended study is represented.

The implementation of an IEA is part of establishing a set of architectural guidelines that ensure comprehensive development between models and interenterprise needs, with joint business processes and ICT. This set of ICT strategic guidelines must be based on joint strategic planning and corporate recognition of business strategies and activities that support such planning. These guidelines will 
also be responsible for spawning necessary information for the joint operation of organizations and technologies required to support joint operations and processes for implementing new technologies in response to changing needs and jointly involved organizations.

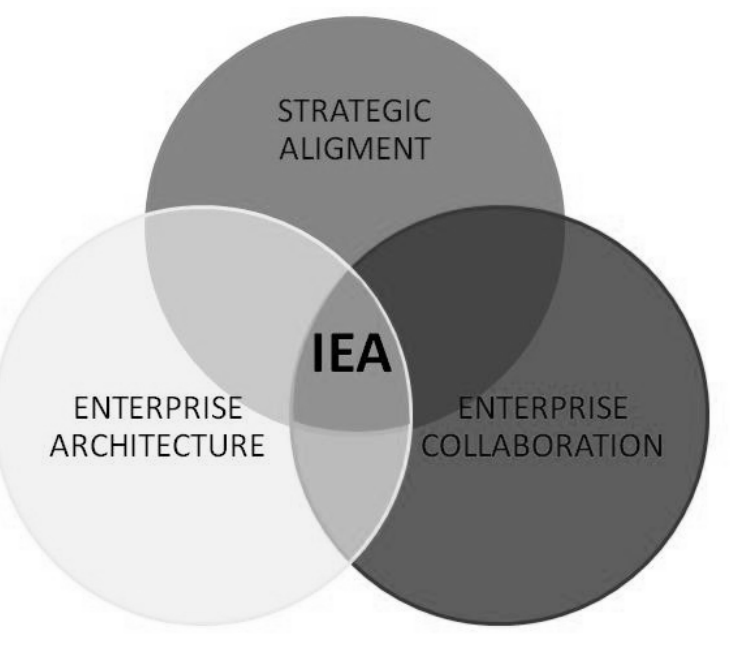

Fig. 1. Origin of the IEA concept

The importance of the IEA resides ultimately in its utility for the joint organization, which will remain there as long as it will be updated every time there are changes in joint strategic planning, changes in vital business processes, or changes in ICT that support vital processes.

Fig. 2 describes the main conceptual elements of an IEA. The core of the IEA is the collaborative process (CP), which is triggered by the necessity of collaboration between network partners. As a result, the collaborative process begins following a minimum of seven activities identified as vital. If the joint organization really wants to take advantage of that collaborative process, then it is necessary to involve the joint organization in an alignment process, taking into account the elements of the strategic alignment model (SAM).Thus, it is also important to adapt these to a collaborative organization, where joint business and IT dimensions have to have a clear functional integration, and the external and internal elements of business and IT have to have a strategic fit. To achieve this alignment, it is necessary to enforce the utilization of enterprise architecture and its main elements (EEA): methodology, framework and language modelling.

On the other hand, it is evident that technology plays a crucial role in this conceptual model. It has been discussed in previous paragraphs through the utilization of technology as Internet of Things or Web of Services. Therefore it is possible to enable collaborative networks to make decisions in real time, allowing agility, accuracy and effectiveness in the joint processes. 


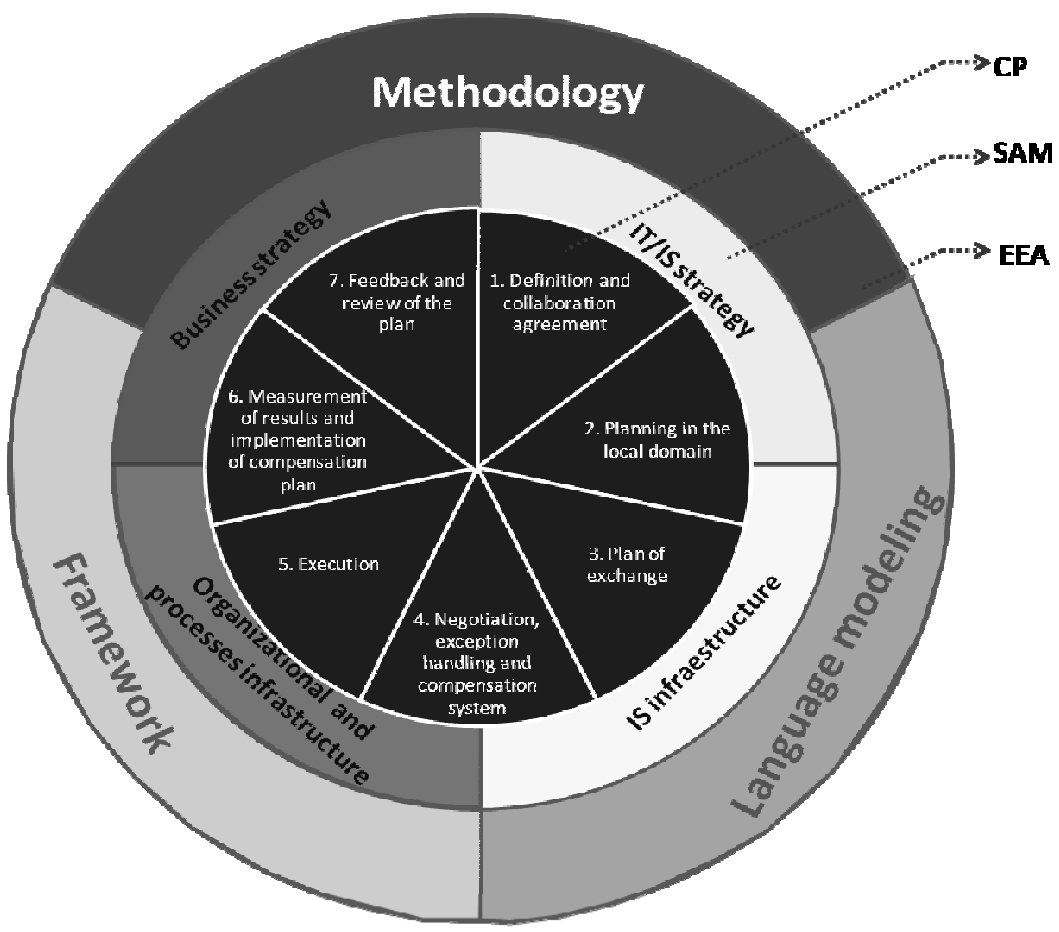

Fig. 2. Conceptual model of IEA

According to the European Commission, in 2025, the Internet will become entirely universal in all business environments, and new business models will be designed to support competition and enterprise collaboration. This trend is known as "internet of the future based on enterprise systems". The Future Internet networked enterprises [FInES] involves the following basic pillars: Internet of Things (IoT), Internet of Services (IoS), Internet of People (IoP), Internet of Knowledge (IoK) [20].

\section{$5 \quad$ Critical View}

The fields of enterprise collaboration, strategic alignment and enterprise architecture have made significant progress in the last years in terms of research and applications in the industry. More recently, each one of these fields is seeking to collaborate in a complementary way. Current research proposes the fusion of these three fields in order to extract the main elements that give origin to the concept of IEA. Due to the existence of different perspectives in the literature, this research is looking to contribute to existing research with a more theoretical foundation.

\section{Conclusions and Further Work}

In order to fuse and implement the principles of collaboration and strategic alignment, we propose the use of enterprise engineering through the use of enterprise architectures. 
Enterprise architectures are tools that provide business concepts, models and tools that enable the integration of the elements that comprise it. The supply chains or networks are a set of related companies where the principles of enterprise architectures can be extended to this type of collaborative organizations.

In relation to research that combines the use of strategic alignment, business collaboration and enterprise architectures, there are no references found that take into simultaneous account these three fields of knowledge, but there are only articles that deal with different ways to combine two of these three disciplines.

The line of research that arises from this analysis is to make a proposal for interenterprise architecture in the context of collaborative networks based in Internet of the future, looking to achieve a real strategic alignment between joint business and joint information technology. This line approaches and combines the three disciplines analysed: enterprise architecture, strategic alignment and business collaboration.

We want to continue working in this line of research seeking a proposal in future papers of a Reference Architecture for Collaborative Networks based in Future Internet.

\section{References}

1. Information Society and Media European Commission: FInES Cluster Position Paper. Future Internet Enterprise Systems (FInES) Cluster (September 2009)

2. Vargas, A., Boza, A., Cuenca, L.: Lograr la alineación estratégica de negocio y las tecnologías de la información a través de Arquitecturas Empresariales: Revisión de la Literatura. In: Cartagena, XV Congreso de Ingeniería de Organización, pp. 1061-1070 (2011a)

3. Vargas, A., Boza, A., Cuenca, L.: Towards Interoperability through Inter-enterprise Collaboration Architectures. In: Meersman, R., Dillon, T., Herrero, P. (eds.) OTM 2011 Workshops. LNCS, vol. 7046, pp. 102-111. Springer, Heidelberg (2011)

4. Vargas, A., Boza, A., Cuenca, L., Ortiz, A.: The importance of strategic alignment in enterprise collaboration. In: 6th International Conference on Industrial Engineering and Industrial Management, Vigo (2012)

5. Henderson, J., Venkatraman, N.: Strategic alignment: Leveraging information technology for transforming organizations. IBM Systems Journal 32(1), 472-484 (1993)

6. Luftman, J.: Assessing Business-IT alignment maturity. Communications of the Association for Information Systems 4 (2000)

7. Cuenca, L., Boza, A., Ortiz, A.: An enterprise engineering approach for the alignment of business and information technology strategy. International Journal of Computer Integrated Manufacturing 24(11) (2011)

8. Kilger, C., Reuter, B., Stadtler, H.: Collaborative Planning. In: Stadtler, H., Kilger, C. (eds.) Supply Chain Management and Advanced Planning-Concepts, Models Software and Case Studies, pp. 263-284. Springer, Heidelberg (2008)

9. Audy, J., Lehoux, N., D'Amours, S.: A framework for an efficient implementation of logistics collaborations. International Transactions in Operational Research, 1-25 (2010)

10. Stadtler, H.: A framework for collaborative planning and state-of-the-art. OR Spectrum 31 , 5-30 (2010)

11. CIMOSA Association: CIMOSA Primer on key concepts, purpose and business value, http: / / cimosa.cnt.pl/ 
12. Chen, D., Vallespir, B., Doumeingts, G.: GRAI integrated methodology and its mapping onto generic enterprise reference architecture and methodology. Computers in Industry 33, 387-394 (1997)

13. Williams, T., Li, H.: PERA and GERAM enterprise reference architectures in enterprise integration. Information Infrastructure Systems for Manufacturing, 1-27 (1998)

14. Ortiz, A.: Propuesta para el Desarrollo de Programas de Integración Empresarial en Empresas Industriales. Aplicación a una Empresa del Sector Cerámico. Ph.D Dissertation. Universidad Politécnica de Valencia (1998)

15. The Open Group, https : / /www. opengroup.org/index.htm

16. Chalmeta, R., Grangel, R.: ARDIN extension for virtual enterprise integration. The Journal of Systems and Software 67 (2003)

17. Scheer, A., Schneider, K.: ARIS - Architecture of Integrated Information. In: Handbook on Architectures of Information Systems. International Handbooks on Information Systems, s.1., vol. 3, pp. 605-623 (2006)

18. Bernard, S.: An introduction to enterprise architecture. Author House, Bloomington (2005)

19. Cuenca, L., Ortiz, A., Boza, A.: Arquitectura de Empresa. Visión General. In: IX Congreso de Ingeniería de Organización, Gijón, pp. 1-8 (2005)

20. Burlacu, G., Stanescu, A., Sacala, I., Cojocaru, L.: Development of a Modeling Framework for Future Internet Enterprise Systems. In: IEEE 16th International Conference on System Theory, Control and Computing, Sinaia, October 12-14 (2012) 